\title{
Evaluation of gas supply configurations for microbial product formation involving multiple gaseous substrates
}

\author{
Erik B. G. Häusler, Luuk A. M. van der Wielen and Adrie J. J. Straathof*
}

\begin{abstract}
Background: Gaseous substrates such as $\mathrm{O}_{2}$ and $\mathrm{CO}_{2}$ are often required in fermentation processes. However, a simple methodology to compare different gas supply strategies using gaseous substrates from different sources is missing.

Results: In this study, we present a methodology to identify and theoretically compare different configurations to supply mixtures of gaseous compounds to fermentations that consume these gases. For the different configurations that were identified, all gas flow rates can be calculated in terms of other process parameters such as optimal concentrations of the gaseous compounds in the liquid phase, top pressures of the fermentation, and consumption/production rates. The approach is demonstrated for fumaric acid fermentation with Rhizopus delemar, which consumes $\mathrm{O}_{2}$ and can theoretically produce or consume $\mathrm{CO}_{2}$. Three different gas supply configurations were identified: Air supplemented with $\mathrm{O}_{2}$, a mixture of $\mathrm{O}_{2}$ and $\mathrm{CO}_{2}$, and air supplemented with $\mathrm{CO}_{2}$. All three configurations lead to gas supply costs in the same order of magnitude. $\mathrm{O}_{2}$ and $\mathrm{CO}_{2}$ prices and consumption rates determine which configuration is best. However, the overall production costs will not be dominated by the gas costs, but by the glucose costs.
\end{abstract}

Conclusions: The presented methodology enables a simple way to identify and compare different gas supply strategies for fermentations that require more than one gaseous substrate. This includes the costs for compression of gases. Other substrate costs are easily added for overall process optimization.

Keywords: Gas-liquid mass transfer, Bioreactors, Modeling, Bioprocess design, Fumaric acid, Multiple gaseous substrates

\section{Background}

Biotechnological production of fuel and (bulk) chemicals from sustainable resources is a promising alternative for petrol-based processes. However, in many cases, petrochemical routes are economically more attractive. Often, the fermentation is one of the main contributors to the overall production cost, and much effort is spent to reduce the costs of this unit operation, for example utilization of lignocellulosic carbon sources (Straathof 2011). Another way to reduce fermentation costs is recycling of microbial mass, which decreases the consumption of substrate for the production of microbial mass.

${ }^{*}$ Correspondence: a.j.j.straathof@tudelft.nl

Department of Biotechnology, Delft University of Technology, Julianalaan 67, 2628 Delft, The Netherlands
High-density fermentation increases the volume-specific productivity and leads to smaller bioreactors, thus lower capital expenditures (CAPEX). In situ product removal is investigated for cases that product inhibition prevents high final titers.

Next to substrates that can be supplied through a liquid feed, many fermentations need substrates that are gaseous at fermentation conditions, i.e., oxygen in countless aerobic fermentations. If possible, air is used for oxygen supply, because it is cheap, and the off-gas is generally vented after a single pass through the bioreactor. However, when using air the driving force for oxygen transfer from gas to liquid phase can become too small to sustain a sufficiently high oxygen transfer rate (OTR). This can be overcome by operating at higher top pressures

\section{Springer Open}


and/or increasing the oxygen mole fraction in the feed gas (van 't Riet and Tramper 1991). The drawback of the first method is that a higher top pressure leads to higher energy consumption, and of the second method that pure gases have to be purchased, or produced, which also introduces additional operational expenditures (OPEX).

The point concerning supply of gases becomes especially important when a fermentation requires a mixture of gaseous substrates, and when this mixture is not available as cost-free gas stream. Table 1 shows several cases where this applies. For example, recent research showed that aerobic fumaric acid (FA) fermentations using Rhizopus delemar benefit from increased partial $\mathrm{CO}_{2}$ pressures up to $p_{\mathrm{CO}_{2}}=0.1$ bar (Roa Engel et al. 2011). This effect is related to an anaplerotic reaction in the organism's metabolic network in which pyruvate carboxylase fixes $\mathrm{CO}_{2}$. The need for a certain partial $\mathrm{CO}_{2}$ pressure was also reported for citric acid fermentations with Aspergillus niger (Papagianni 2007). The necessary $\mathrm{CO}_{2}$ is produced by the organism, but was stripped from the medium by increased aeration rates which led to lower product yields. McIntyre and McNeil (McIntyre and McNeil 1997) showed for this fermentation that $2 \% \mathrm{CO}_{2}$ led to increased product concentration. Too high $\mathrm{CO}_{2}$ percentages can lead to lower product concentrations.

As stated before, air is usually vented after a single pass through the bioreactor. However, for other gas feeds, for example air enriched by $\mathrm{O}_{2}$, venting the off-gas after a single pass through the bioreactor would lead to losses of valuable gases. These losses can be reduced by recirculating the off-gas. A closed off-gas recycling when using pure $\mathrm{O}_{2}$ for aeration was presented by de Ory et al. (2004) for vinegar production to avoid losses of ethanol via offgas, but the economic feasibility of the system compared to the conventional aeration method was not evaluated. Chang et al. (2010) presented such an evaluation for an industrial-scale poly(3-hydroxybutyrate) fermentation.
Their results showed that an off-gas recycle system including pressure swing adsorption for production of pure $\mathrm{O}_{2}$ leads to lower fermentation costs than conventional aeration with air.

This raises several questions: Will an off-gas recycle system generally lead to lower costs than aeration with air, even though the gaseous substrates would have to be bought? Would such a system also work when two or more gaseous compounds need to be controlled? Are there other alternative gas supply configurations which would lead to even lower costs? However, a systematic evaluation of different gas supply configurations for industrial fermentations is lacking. The questions are addressed by presenting a methodology to define mathematically defined and physically feasible gas supply configurations based on a general case. For each of these cases, relations are derived to size all gas streams which enter or leave the bioreactor.

The methodology is illustrated for an FA fermentation with $R$. delemar, because it requires the presence of two gases, $\mathrm{O}_{2}$ and $\mathrm{CO}_{2}$, in the liquid phase. Still, the methodology enables a simple way to evaluate several gas supply configurations. First, a general case is defined which is mathematically underdetermined. Then three different and mathematically determined $\mathrm{O}_{2}$ and $\mathrm{CO}_{2}$ supply configurations for FA fermentation are derived from the general case: (1) $\mathrm{CO}_{2}$-enriched air with vented off-gas, (2) off-gas recycle with $\mathrm{CO}_{2}$ and $\mathrm{O}_{2}$ feed (zero gas emission), and (3) $\mathrm{O}_{2}$-enriched air with vented off-gas. All gas flow rates entering and leaving the system are derived for the three cases, and the cases are evaluated in terms of gas supply costs and overall production costs (including additional substrates and energy consumption).

\section{Methods}

A stirred tank reactor at steady state is used as a basis for the derivation of relations of the gas streams, and

Table 1 Examples of microbial product formation involving multiple gaseous substrates

\begin{tabular}{|c|c|c|c|c|}
\hline Organism & Product(s) & Gaseous substrate & Gas feed & Source \\
\hline Rhizopus delemar & Fumaric acid & $\mathrm{O}_{2}, \mathrm{CO}_{2}$ & Air, $\mathrm{CO}_{2}$ & (Roa Engel et al. 2011) \\
\hline Saccharomyces cerevisiae & Malic acid & $\mathrm{O}_{2}, \mathrm{CO}_{2}$ & Air, $\mathrm{O}_{2}, \mathrm{CO}_{2}$ & (Zelle et al. 2010) \\
\hline S. cerevisiae & Succinic acid & $\mathrm{O}_{2}, \mathrm{CO}_{2}$ & Air, $\mathrm{O}_{2}$ & Jansen and van Gulik (2014) \\
\hline Corynebacterium glutamicum & Cell mass & $\mathrm{O}_{2}, \mathrm{CO}_{2}$ & Air, $\mathrm{O}_{2}, \mathrm{CO}_{2}$ & (Bäumchen et al. 2007) \\
\hline Clostridium carboxidivorans & Ethanol & $\mathrm{CO}, \mathrm{CO}_{2}, \mathrm{H}_{2}$ & $\mathrm{CO}, \mathrm{CO}_{2}, \mathrm{H}_{2}$ & (Hurst and Lewis 2010) \\
\hline Alkalibaculum bacchi and C. propionicum & Alcohols & $\mathrm{CO}, \mathrm{CO}_{2}, \mathrm{H}_{2}$ & Syngas & (Liu et al. 2014) \\
\hline Mycobacterium sp. & Ethylene oxide & Ethylene, $\mathrm{O}_{2}$ & Ethylene, $\mathrm{O}_{2}$ & (de Bont et al. 1983) \\
\hline Methylosinus sp. & Propylene oxide & Propylene, $\mathrm{O}_{2}$ & Propylene, $\mathrm{O}_{2}$ & (Hou 1984) \\
\hline Methylosinus sp. & 2-butanol & Butane, $\mathrm{O}_{2}$ & Butane, $\mathrm{O}_{2}$ & (Patel et al. 1980) \\
\hline Brevibacterium sp. & Glutamic acid & $\mathrm{O}_{2}, \mathrm{NH}_{3}$ & $\mathrm{O}_{2}, \mathrm{NH}_{3}$ & (Nagy et al. 1995) \\
\hline
\end{tabular}


gas and liquid phases are assumed to be ideally mixed except near the gas-liquid interface. The gases are treated as ideal gases because fermentations are generally operated at relatively low pressures ( $p_{\text {tot }}<10 \mathrm{bar}$ ). For example, Song et al. (2007) show the ideal behavior of Mannheimia succiniciproducens in terms of growth and succinic acid production up to a partial $\mathrm{CO}_{2}$ pressure of 1 bar. Therefore, non-ideal behavior can be neglected (Green and Perry 2007). When higher pressures are considered, a correction using the fugacity coefficient should be applied. Furthermore, the liquid phase is assumed to have the properties of pure water, a fixed volume, and no pressure gradients due to height or so. The aim of the methodology is to calculate the gas inflow rates as a function of the other process parameters.

\section{Gas flow rates as a function of production rates, total pressure, and partial gas pressures}

We start by defining steady-state mass balances for each component in the gas phase (see Eq. 1):

$$
F_{i}^{\text {in }}=F_{i}^{\text {out }}-r_{i} \text {. }
$$

The volume-specific production rate $r_{i}$ of component $i$ by the bioreaction can be positive, negative in case of consumption, or zero in case of inert components such as $\mathrm{N}_{2}$ when air is used for $\mathrm{O}_{2}$ supply. Different from usual conventions, flow rates $F_{i}$ and production rates $r_{i}$ are expressed in mole per $\mathrm{m}^{3}$ bioreactor liquid per second, because the absolute fermentor volume is not known. The ratio of partial pressures $p_{i} / p_{j}$ of two components $i$ and $j$ in the bioreactor equals the ratio of the gas outflows of these two components (Eq. 3). The relation is easily derived: the mole fraction $y_{i}$ of component $i$ in the gas phase equals the ratio of its partial pressure $p_{i}$ and the total pressure $p_{\text {tot }}$ Similarly, it also equals the ratio of its partial molar outflow $F_{i}^{\text {out }}$ and the total molar outflow $F_{\text {tot }}^{\text {out }}$ (Eq. 2). If we divide the mole fractions of two components, we arrive at Eq. 3.

$$
\begin{aligned}
& y_{i}=\frac{p_{i}}{p_{\text {tot }}}=\frac{F_{i}^{\text {out }}}{F_{\text {tot }}^{\text {out }}} \\
& \frac{F_{i}^{\text {out }}}{F_{j}^{\text {out }}}=\frac{p_{i}}{p_{j}}
\end{aligned}
$$

Besides being present in a cheap gas stream, an inert gas in combination with the pressure in the bioreactor can also be used to adjust the partial pressures of multiple components $i$ to a specific optimum.

$$
p_{\text {Inert }}=p_{\text {tot }}-\sum p_{i}
$$

All mass balances and pressure-flow relations are linear in terms of the gas flow rates, and this results in $2 n-1$ linear equations with $2 n$ unknowns, where $n$ is the total number of components in the gas phase. The unknowns in the equations are the gas in- and outflow rates of each component $\left(F_{i}^{\text {in }}\right.$ and $\left.F_{i}^{\text {out }}\right)$. The partial pressures are known variables and their elimination from the system of equations is discussed in the next section. The total pressure is set by the process operator. There are several options to solve the resulting system of equations. First, one of the gas flow rates could be fixed, thereby reducing the number of unknowns. Another option is to find another independent equation without new unknowns. This can be achieved by fixing the ratio of two components in the gas feed, which yields an additional pressure-flow relation. This is essentially the case when air is used as a single $\mathrm{O}_{2}$ source for an aerobic fermentation. Now, the system of equations can be solved to express all flow rates $F_{i}$ as a function of optimal partial gas pressures, the total pressure in the bioreactor, and the components' production/consumption rates.

\section{Elimination of $p_{i}$ through mass transfer relation and Henry's law}

Using the aforementioned relations, we can express all gas flow rates as a function of the production rates, total system pressure, and partial gas pressures. However, the microorganism senses the concentration of $i$ in the liquid phase, not the partial pressure in the gas phase. To eliminate the partial gas pressures, we need the steadystate mass balance over the liquid phase (Eq. 5), the mass transfer relation (Eq. 6), and Henry's law (Eq. 7).

$$
\begin{aligned}
& T_{i}+r_{i}=0 \\
& T_{i}=k_{L, i} a\left(c_{i}^{*}-c_{i}\right) \\
& p_{i}=H_{i} x_{i}
\end{aligned}
$$

Here, $T_{i}$ is the mass transfer rate from gas to liquid phase $\left[\mathrm{mol} /\left(\mathrm{m}^{3} \mathrm{~s}\right)\right], k_{L, i}$ is the mass transfer coefficient of $i$ in the liquid phase, $a$ is the specific gas-liquid interface area $\left[\mathrm{m}^{2} / \mathrm{m}^{3}\right], c_{i}{ }^{*}$ is the concentration of $i$ in the liquid phases $\left[\mathrm{mol} / \mathrm{m}^{3}\right]$ at the gas-liquid interface, and $c_{i}$ is the concentration of $i$ in the bulk of liquid phase [mol/ $\mathrm{m}^{3}$ ]. The interfacial concentration in the liquid phase is related to the partial pressure of $i$ in the gas phase according to Henry's law. $H_{i}$ is the Henry's law constant, and depending on its definition it has different units. Using the definition of Eq. 7 where $x_{i}$ is the mole fraction of $i$ in the liquid phase at equilibrium, $H_{i}$ has pressure units. The exact composition of the liquid is unknown, but by assuming that the bulk only consists of water, the molar 
volume $V_{\mathrm{mol}}\left[\mathrm{m}^{3} / \mathrm{mol}\right]$ of water can be used to express $c_{i}{ }^{*}$ as a function of $x_{i}$.

$$
c_{i}^{*}=\frac{x_{i}}{V_{\mathrm{mol}}}
$$

Eliminating $c_{i}^{*}, x_{i}$, and $T_{i}$ from Eqs. 5-8 and solving for the partial pressure yields

$$
p_{i}=V_{\mathrm{mol}} H_{i}\left(\frac{\left(-r_{i}\right)}{k_{L, i} a}+c_{i}\right) .
$$

The final step is substituting the partial pressures into the inflow relations that were derived in the previous section. This yields the flow rates as a function of optimal concentrations in the liquid phase, Henry's constant, volume-specific production rates, mass transfer coefficients, and the total pressure in the bioreactor.

\section{Energy for gas supply}

Pumping gas into pressurized vessels demands energy for compression. The energy depends on the gas mass inflow rate $F_{m}^{\text {in }}\left[\mathrm{kg} /\left(\mathrm{m}^{3} \mathrm{~s}\right)\right]$, the ratio of the gas pressure at its source $p_{\text {source }}$ and the pressure $p_{\text {tot }}$ in the bioreactor. The hydrostatic pressure in the vessel is neglected. The energy demand $W\left[\mathrm{~J} /\left(\mathrm{m}^{3} \mathrm{~s}\right)\right]$ can be calculated by the general Bernoulli equation assuming adiabatic compression of an ideal gas while neglecting friction and changes in potential and kinetic energy (Sinnott 2005).

$$
W=F_{m}^{\text {in }}\left(\frac{p_{\text {Source }}}{\rho_{\text {Source }}} \frac{\kappa}{\kappa-1}\left\{\left(\frac{p_{\text {tot }}}{p_{\text {Source }}}\right)^{\frac{\kappa-1}{\kappa}}-1\right\}\right)
$$

Kappa $(\kappa)$ equals the ratio of specific heats of the gas at constant volume $\left(C_{V}\right)$ and at constant pressure $\left(C_{p}\right)$. We must distinguish between different possible sources as some are pressurized and others are at ambient conditions. For example, air at ambient conditions must be compressed when the fermentation is operated at elevated pressures, but this is not necessary when the gas is already pressurized. For the rest of this study, it is assumed that purchased pure gases are pressurized.

\section{Costs}

To be able to select one of the gas supply configurations, we must determine the associated fermentation costs per kilogram product $G_{\text {tot }}\left[\$ / \mathrm{kg}_{P}\right]$. Here, investments are neglected for simplicity, and only the sum of gas costs $G_{i}$ $\left[\$ / \mathrm{kg}_{P}\right]$ and energy costs for compression $G_{W}\left[\$ / \mathrm{kg}_{P}\right]$ is considered.

$$
G_{\mathrm{tot}}=G_{W}+\sum_{i} G_{i}
$$

At this stage, all gas flows and production rates as well as energy demand and substrate consumption are given as volume-specific quantities and they need to be converted into costs per kilogram product $\left(G_{i}\right.$ and $\left.G_{W}\right)$. Therefore, each rate is divided by the volume-specific rate $r_{P, m}\left[\mathrm{~kg} /\left(\mathrm{m}^{3} \mathrm{~s}\right)\right]$ of the product. This yields the amount of gas or associated energy demand per kilogram product, and multiplication by the associated prices $\left(P_{i}\left[\$ / \mathrm{kg}_{i}\right]\right.$ and $\left.P_{W}[\$ / J]\right)$ yields the costs per kilogram product. Molar substrate consumption rates $r_{i}\left[\mathrm{~mol} /\left(\mathrm{m}^{3} \mathrm{~s}\right)\right]$ are easily converted to mass-based rates $r_{i, m}\left[\mathrm{~kg} /\left(\mathrm{m}^{3} \mathrm{~s}\right)\right]$ by multiplication with the molar mass of the respective compound.

$$
G_{i}=-\frac{r_{i, m}}{r_{p, m}}\left(P_{i}\right) \text { and } G_{W}=\frac{W}{r_{p, m}}\left(P_{W}\right)
$$

\section{Results}

The methodology has been applied to an FA fermentation with the fungus $R$. delemar, formerly known as $R$. oryzae. The fermentation is aerobic, but $\mathrm{CO}_{2}$ also plays an important role (Roa Engel et al. 2011), and it might even be consumed by the bioreaction instead of produced. The cause for this behavior is related to the metabolic network, and it is discussed during the derivation of the gas production/consumption rates in "Derivation of gas production rates" section. Nonetheless, this information was sufficient to define three different gas supply configurations, and the gas inflow relations were derived for all compounds of each separate case.

\section{Gas supply configurations}

The first step is to identify the gas supply configurations that can maintain desired partial $\mathrm{O}_{2}$ and $\mathrm{CO}_{2}$ pressures $\left(p_{\mathrm{O}_{2}}\right.$ and $\left.p_{\mathrm{CO}_{2}}\right)$ for this FA fermentation. The most general case is supply of both necessary gases $\left(\mathrm{O}_{2}\right.$ and $\mathrm{CO}_{2}$ ) and an inert gas stream such as $\mathrm{N}_{2}$ in case $p_{\text {tot }}>p_{\mathrm{O}_{2}}+p_{\mathrm{CO}_{2}}$ (Fig. 1a), and vent off-gas. So, we start by defining the $\mathrm{O}_{2}, \mathrm{CO}_{2}$, and $\mathrm{N}_{2}$ mass balances over the gas phase (Eqs. 13-15) and the pressure-flow relations for $\mathrm{O}_{2}$ and $\mathrm{CO}_{2}$ on the basis of $\mathrm{N}_{2}$ (Eqs. 16 and 17). In total, there are five equations with six unknowns $\left(F_{\mathrm{O}_{2}}^{\text {in }}, F_{\mathrm{O}_{2}}^{\text {out }}, F_{\mathrm{CO}_{2}}^{\text {in }}, F_{\mathrm{CO}_{2}}^{\text {out }}, F_{\mathrm{N}_{2}}^{\text {in }}\right.$, and $\left.F_{\mathrm{N}_{2}}^{\text {out }}\right)$ and therefore, as discussed before, an additional relation is needed, or one variable has to be fixed at a particular value.

$$
\begin{aligned}
& F_{\mathrm{CO}_{2}}^{\text {in }}=F_{\mathrm{CO}_{2}}^{\text {out }}-r_{\mathrm{CO}_{2}} \\
& F_{\mathrm{O}_{2}}^{\text {in }}=F_{\mathrm{O}_{2}}^{\text {out }}-r_{\mathrm{O}_{2}} \\
& F_{\mathrm{N}_{2}}^{\text {in }}=F_{\mathrm{N}_{2}}^{\text {out }} \\
& \frac{F_{\mathrm{CO}_{2}}^{\text {out }}}{F_{\mathrm{N}_{2}}^{\text {out }}}=\frac{p_{\mathrm{CO}_{2}}}{p_{\mathrm{N}_{2}}}
\end{aligned}
$$




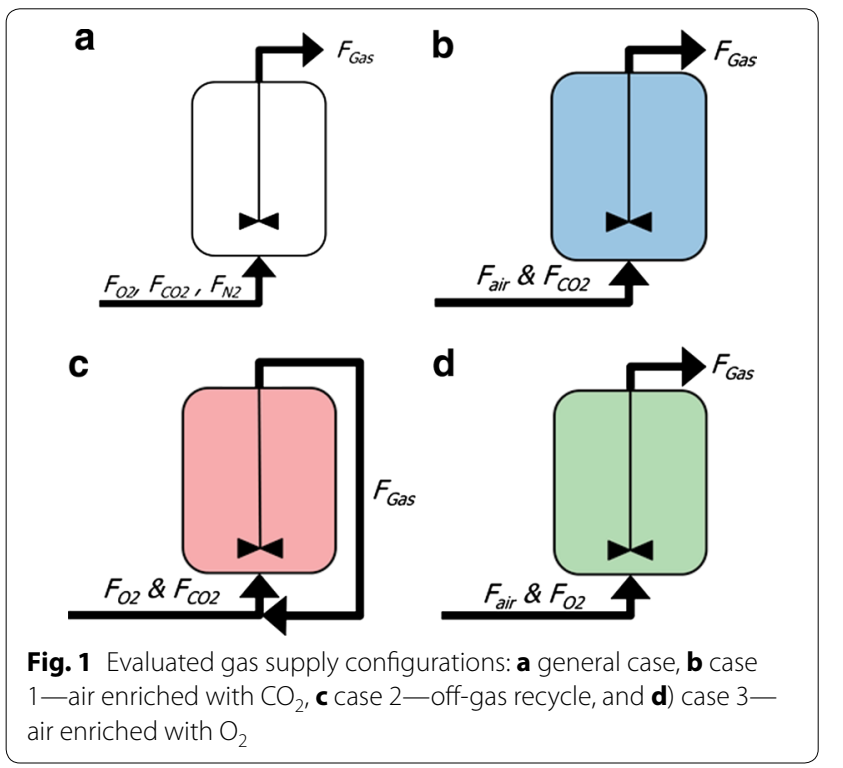

$$
\frac{F_{\mathrm{O}_{2}}^{\text {out }}}{F_{\mathrm{N}_{2}}^{\text {out }}}=\frac{p_{\mathrm{O}_{2}}}{p_{\mathrm{N}_{2}}}
$$

\section{Case 1: air supplemented with $\mathrm{CO}_{2}$}

As proposed by Roa Engel et al. (2011), the bioreactor can be fed with air supplemented with $\mathrm{CO}_{2}$ (Fig. 1b), and the off-gas is vented after a single pass through the bioreactor. This case is referred to as case 1 . The mass balances over the gas phase and pressure-flow relations for $\mathrm{O}_{2}$ and $\mathrm{CO}_{2}$ in terms of $\mathrm{N}_{2}$ are the same as for the general case (Eqs. 13-17), but we can add an additional pressure-flow relation for the $\mathrm{O}_{2}$ and $\mathrm{N}_{2}$ inflow, because the ratio of the partial $\mathrm{O}_{2}$ and $\mathrm{N}_{2}$ pressures in the gas feed is known.

$$
\frac{F_{\mathrm{O}_{2}}^{\mathrm{in}}}{F_{\mathrm{N}_{2}}^{\mathrm{in}}}=\frac{p_{\mathrm{O}_{2}}^{\text {air }}}{p_{\mathrm{N}_{2}}^{\text {air }}}=\frac{0.21}{0.79}
$$

The costs of case 1 depend on $F_{\mathrm{CO}_{2}}^{\mathrm{in}}$ and energy requirements to compress the air for $F_{\text {Air }}^{\text {in }}$ Therefore, we need to express both flow rates as a function of $p_{\text {tot }}, p_{i}$, and $r_{i}$. The $\mathrm{CO}_{2}$ inflow is found by taking Eqs. 13-18 and eliminating all other flows $\left(F_{\mathrm{O}_{2}}^{\text {in }}, F_{\mathrm{O}_{2}}^{\text {out }}, F_{\mathrm{N}_{2}}^{\text {in }}, F_{\mathrm{N}_{2}}^{\text {out }}\right.$ and $\left.F_{\mathrm{CO}_{2}}^{\text {out }}\right)$.

$$
F_{\mathrm{CO}_{2}}^{\mathrm{in}}=\frac{-r_{\mathrm{O}_{2}} 0.79 p_{\mathrm{CO}_{2}}}{\left(0.21 p_{\mathrm{N}_{2}}-0.79 p_{\mathrm{O}_{2}}\right)}-r_{\mathrm{CO}_{2}}
$$

Then, we substitute the partial pressure of the inert gas (Eq. 4) and relations for the partial $\mathrm{O}_{2}$ and $\mathrm{CO}_{2}$ pressures (Eq. 9) into the $\mathrm{CO}_{2}$ inflow relation (Eq. 19).
Next, the air inflow rate needs to be determined. This flow is directly related to the $\mathrm{O}_{2}$ inflow (Eq. 21), which is derived similarly as the $\mathrm{CO}_{2}$ inflow. Only the result is shown below. The relations for $\mathrm{O}_{2}$ and $\mathrm{CO}_{2}$ partial pressure are not substituted into this equation to reduce its complexity.

$$
\begin{aligned}
F_{\text {air }}^{\text {in }} & =\frac{F_{\mathrm{O}_{2}}^{\text {in }}}{0.21} \\
F_{\mathrm{O}_{2}}^{\text {in }} & =\frac{-r_{\mathrm{O}_{2}}}{1-\frac{0.79}{0.21} \frac{p_{\mathrm{O}_{2}}}{p_{\mathrm{N}_{2}}}}
\end{aligned}
$$

In addition to the gas cost, the energy for compression of gases to the desired top pressure needs to be taken into account, too. In case 1, air needs to be compressed from atmospheric to the desired top pressure. Pure $\mathrm{CO}_{2}$ is added from a pressurized source and therefore does not add to the energy requirements for compression.

\section{Case 2: off-gas recycle with $\mathrm{O}_{2}$ and $\mathrm{CO}_{2}$ feed (zero gas emission)}

The second case is found when one of the gas outflows is set to 0 . By doing so, all other gas outflows are removed as well. All the introduced gas can be kept in the bioreactor, but in practice it will be easier to use an off-gas recycle system (Fig. 1). Thus, the off-gas is fed to the bioreactor again, and only consumed amounts of gases have to be supplied. As indicated, the fermentation is operated at a given set of desired partial pressures. Pure $\mathrm{O}_{2}$ and $\mathrm{CO}_{2}$ are supplied to the bioreactor, and some $\mathrm{N}_{2}$ can be introduced during the start-up phase of the fermentation to achieve $p_{\text {tot }}$. The costs for case 2 depend on the values of $F_{\mathrm{O}_{2}}^{\mathrm{in}}$ and $F_{\mathrm{CO}_{2}}^{\mathrm{in}}$, which are equal to $-r_{\mathrm{O}_{2}}$ and $-r_{\mathrm{CO}_{2}}$, respectively, according to Eqs. 23 and $24 . F_{\mathrm{O}_{2}}^{\text {in }}$ and $F_{\mathrm{CO}_{2}}^{\mathrm{in}}$ are independent of the system pressure. It should be noted that this configuration implies that $r_{\mathrm{CO}_{2}} \leq 0$. Otherwise, $\mathrm{a} \mathrm{CO}_{2}$ bleed stream would have to be introduced.

$$
\begin{aligned}
& F_{\mathrm{O}_{2}}^{\text {in }}=-r_{\mathrm{O}_{2}} \\
& F_{\mathrm{CO}_{2}}^{\text {in }}=-r_{\mathrm{CO}_{2}}
\end{aligned}
$$

In this case, no additional energy is required for compression, because all gases are already pressurized.

\section{Case 3: air supplemented with $\mathrm{O}_{2}$}

The third case is a bioreactor that is aerated using air and additional pure $\mathrm{O}_{2}$ (Fig. 1d). The off-gas is vented after a single pass through the broth. The desired $\mathrm{CO}_{2}$ partial

$$
F_{\mathrm{CO}_{2}}^{\text {in }}=\frac{-r_{\mathrm{O}_{2}} 0.79 H_{\mathrm{CO}_{2}} V_{\mathrm{mol}}\left(\frac{\left(-r_{\mathrm{CO}_{2}}\right)}{k_{L, \mathrm{CO}_{2}} a}+c_{\mathrm{CO}_{2}}\right)}{\left(0.21 p_{\mathrm{tot}}-0.21 H_{\mathrm{CO}_{2}} V_{\mathrm{mol}}\left(\frac{\left(-r_{\mathrm{CO}_{2}}\right)}{k_{L, \mathrm{CO}_{2}} a}+c_{\mathrm{CO}_{2}}\right)-H_{\mathrm{O}_{2}} V_{\mathrm{mol}}\left(\frac{\left(-r_{\mathrm{O}_{2}}\right)}{k_{L, \mathrm{O}_{2}} a}+c_{\mathrm{O}_{2}}\right)\right)}-r_{\mathrm{CO}_{2}}
$$


pressure is sustained by $\mathrm{CO}_{2}$ produced by the bioreaction, implying that this configuration can only be applied when $r_{\mathrm{CO}_{2}} \geq 0$, because no $\mathrm{CO}_{2}$ is supplied $\left(F_{\mathrm{CO}_{2}}^{\mathrm{in}}=0\right)$. In this case, the mass balances of $\mathrm{O}_{2}$ and $\mathrm{CO}_{2}$ are given by Eqs. 25 and 26, respectively. In contrast to the general case, there are two $\mathrm{O}_{2}$ sources: air and pure $\mathrm{O}_{2}$. The pressure-flow relations remain unchanged. Looking at the system of equations, there are again six equations (three mass balances, Eqs. 15, 25, and 26, and three pressure-flow relations, Eqs. 16-18) and 6 unknowns $\left(F_{\mathrm{O}_{2}}^{\text {in pure }}, F_{\mathrm{O}_{2}}^{\text {out }}, F_{\mathrm{O}_{2}, \text { air }}^{\text {in }}, F_{\mathrm{CO}_{2}}^{\text {out }}, F_{\mathrm{N}_{2}}^{\text {in }}, F_{\mathrm{N}_{2}}^{\text {out }}\right)$.

$$
\begin{aligned}
& F_{\mathrm{O}_{2} \text {,air }}^{\text {in }}+F_{\mathrm{O}_{2} \text {,pure }}^{\text {in }}=F_{\mathrm{O}_{2}}^{\text {out }}-r_{\mathrm{O}_{2}} \\
& F_{\mathrm{CO}_{2}}^{\text {out }}=r_{\mathrm{CO}_{2}}
\end{aligned}
$$

Similar to case 1, expressions for the pure oxygen inflow $F_{\mathrm{O}_{2} \text {,pure }}^{\text {in }}$ (Eq. 27) and the air inflow $F_{\text {Air }}^{\text {in }}$ (Eqs. 28 and 29) can be derived. As before, the relations are presented without substitution of the expression for partial pressures.

$$
\begin{aligned}
& F_{\mathrm{O}_{2}, \text { pure }}^{\text {in }}=r_{\mathrm{CO}_{2}}\left(\frac{p_{\mathrm{O}_{2}}}{p_{\mathrm{CO}_{2}}}-\frac{p_{\mathrm{N}_{2}}}{p_{\mathrm{CO}_{2}}} \frac{0.21}{0.79}\right)-r_{\mathrm{O}_{2}} \\
& F_{\text {air }}^{\text {in }}=\frac{F_{\mathrm{O}_{2}, \text { air }}^{\text {in }}}{0.21} \\
& F_{\mathrm{O}_{2}, \mathrm{Air}}^{\text {in }}=r_{\mathrm{CO}_{2}} \frac{\mathrm{p}_{\mathrm{N}_{2}}}{\mathrm{P}_{\mathrm{CO}_{2}}} \frac{0.21}{0.79}
\end{aligned}
$$

As in case 1, energy is required for compression of air, but the pure oxygen feed is already pressurized and does not add to the energy costs.

\section{Derivation of gas production rates}

Next, we need to define the gas consumption and production rates. FA can be produced from glucose (Glc) via two metabolic pathways (Roa Engel et al. 2008): (1) via the oxidative side of the citrate cycle which produces $\mathrm{CO}_{2}$ and consumes $\mathrm{O}_{2}$, and (2) via the reductive side of the citrate cycle using the anaplerotic route by carboxylation of pyruvate to oxaloacetate. The reaction stoichiometries per mole product of both pathways are given below, but the ratio at which both pathways contribute to the total FA production is not known. Therefore, it is not known whether the fermentation consumes or produces $\mathrm{CO}_{2}$. Available information on this topic is scarce, and when present, it is inconclusive. For simplicity, other reactions, such as cell growth and by-product formation, are neglected.

$$
-\mathrm{Glc}-3 \mathrm{O}_{2}+2 \mathrm{CO}_{2}+4 \mathrm{H}_{2} \mathrm{O}+\mathrm{FA}
$$

$$
-0.5 \mathrm{Glc}-\mathrm{CO}_{2}+\mathrm{H}_{2} \mathrm{O}+\mathrm{FA}
$$

So, it is not possible to identify the exact gas production rates for this fermentation. Still, the range of these rates can be derived from the metabolic pathways. First, we define the mass-specific FA production rate, $q_{P}$, as the sum of both pathways' specific production rates. The oxidative and reductive pathways are defined as pathway 1 and 2 which run at the specific production rates $q_{p_{1}}$ and $q_{p_{2}}$, respectively. Next, the parameter $b$ is defined as the fraction by which pathway 1 contributes to the total production rate. Therefore, the fraction by which pathway 3 contributes to $q_{P}$ is $(1-b)$.

$$
\begin{aligned}
& q_{P}=q_{p_{1}}+q_{p_{2}} \\
& q_{P_{1}}=b q_{P} \\
& q_{P_{2}}=(1-b) q_{P}
\end{aligned}
$$

Similarly, the total specific $\mathrm{O}_{2}$ and $\mathrm{CO}_{2}$ rates, $q_{\mathrm{O}_{2}}$ and $q_{\mathrm{CO}_{2}}$, respectively, are derived (see Fig. 2). The partial specific production rates run according to the stoichiometric coefficients of each reaction multiplied by $q_{p_{1}}$ and $q_{p_{2}}$, respectively. Substitution of Eqs. 33 and 34 for $q_{p_{1}}$ and $q_{p_{2}}$ gives the following expressions for $q_{\mathrm{O}_{2}}$ and $q_{\mathrm{CO}_{2}}-$ in terms of $q_{P}$ and $b$ :

$$
\begin{aligned}
& q_{\mathrm{O}_{2}}=-3 \mathrm{bq}_{P} \\
& q_{\mathrm{CO}_{2}}=(3 b-1) q_{P} .
\end{aligned}
$$

Finally, the specific production rates are multiplied by the microbial concentration, $c_{X}$, which yields the gas production rates per $\mathrm{m}^{3}$.

$$
r_{i}=q_{i} c_{x}
$$

This shows that $\mathrm{O}_{2}$ and $\mathrm{CO}_{2}$ rates $\left(r_{\mathrm{O}_{2}}\right.$ and $r_{\mathrm{CO}_{2}}$, respectively) are functions of the organism's specific

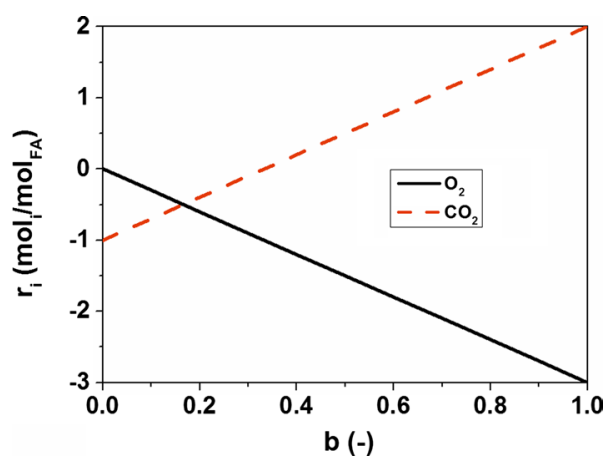

Fig. 2 Gas consumption and production rates per mole product versus pathway distribution $b$ 
fumaric acid production rate $\left(q_{p}\right)$, the chosen fraction of each pathway's contribution to the total specific production rate ( $b$ value), and the microbial concentration in the fermentor. Concerning $b$ values, it should be noted that they vary with microbial strain and fermentor condition. Measuring them is complicated because of the formation of side products and biomass, which grows as pellets or biofilms for the most productive strains. From experimental overall yields of fumaric acid on glucose (Roa Engel et al. 2008), when neglecting that side products and biomass are formed, one can calculate $b$ values in the range of $0.35-1$. Research efforts aim to increase the yield of FA by shifting its production to the reductive side of the citrate cycle, thus moving $b$ toward 0 .

\section{Economic evaluation of gas supply strategies}

After having defined the relations for relevant flow rates, which are related to costs, we can start the economic evaluation of the different gas supply strategies. The exact gas production rates are not known for FA fermentations; therefore, the three cases are compared over the contribution range of both pathways $(b=0-1)$. Case 1 can be evaluated over the whole range of $b$ values. Case 2 applies for $b \leq 1 / 3$, because the net $\mathrm{CO}_{2}$ production is negative up to this point. Case 3 applies for $b \geq 1 / 3$ for similar reasons. Furthermore, the evaluation is performed at several total pressures. The minimum pressure is taken as $1 \mathrm{bar}$ in order to prevent infections from the surroundings. The maximum pressure is taken as 2 bar to prevent too high energy requirements for compression of air. Only cases with positive inflow are considered. A negative inflow of a component implicates that its inflow is too high to maintain desired conditions in the bioreactor. For example, the amount of $\mathrm{O}_{2}$ in air could be too high. In this case, the feed could be altered either by removing $\mathrm{O}_{2}$ at the cost of an additional unit operation, or by increasing the amount of inert gas (i.e., $\mathrm{N}_{2}$ ). The second option would lead to additional gas costs.

\section{Choice of parameters}

The values used for the parameters in the flow relations $\left(k_{L, i} a, c_{i}, H_{i}, p_{\text {tot }}, r_{i}\right)$ are summarized in Table 2 . The gasliquid mass transfer coefficients depend on several casespecific parameters such as geometry of vessel and stirrer, stirrer speed, temperature, bubble size, and composition of liquid phase. A comprehensive review on empirical relations for different reactor types to predict $k_{L, i} a$ was presented by Garcia-Ochoa and Gomez (2009), and for $\mathrm{O}_{2}$ its value was shown to be in the range of $10^{-1}-10^{-4}$ $\mathrm{s}^{-1}$ (Riet and Tramper 1991). For the ease of this evaluation, $k_{L, i} a$ is set to be constant. According to the film theory (Cussler 2009), liquid mass transfer coefficients of other compounds are estimated by the relationship between mass transfer coefficients and diffusivities in the liquid phase.

$$
\frac{k_{L, \mathrm{O}_{2}} a}{k_{L, \mathrm{CO}_{2}} a}=\frac{D_{L, \mathrm{O}_{2}}}{D_{L, \mathrm{CO}_{2}}}
$$

The optimal $\mathrm{CO}_{2}$ concentration in the bulk of the liquid phase and the associated specific FA production rate are based on the study of Roa Engel et al. (2011). The dissolved $\mathrm{CO}_{2}$ concentration is calculated under the assumption of gas-liquid equilibrium. This assumption is based on the results of the same study which indicated $\mathrm{CO}_{2}$ production rates close to 0 . This implies that the concentration in the bulk liquid is close to the concentration at the gas-liquid interface. However, this cannot be assumed for $\mathrm{O}_{2}$. In another study (Fu et al. 2010), it was shown that $30-80 \%$ dissolved oxygen is beneficial for FA production. Using the lower limit, $\mathrm{CO}_{2}$ is set to $30 \%$ of the equilibrium concentration between water and air at ambient conditions. The molar volume of the liquid was calculated from the density $\left(\rho\right.$ in $\left.\mathrm{kg} / \mathrm{m}^{3}\right)$ of pure water at $308 \mathrm{~K}$ and atmospheric pressure.

Chemical and energy prices used for the economic evaluation are also summarized in Table 2. The indicated price ranges for $\mathrm{CO}_{2}$ and $\mathrm{O}_{2}$ are based on the following information and considerations. For $\mathrm{O}_{2}$, Monteiro et al. (2009) used $0.015 \$ / \mathrm{kg}_{\mathrm{O}_{2}}$ which is based on information of the company PRAXAIR. This seems to be relatively low price, because the same company stated in a presentation from 2005 a price range from 0.015 to $0.060 \$ / \mathrm{kg}_{\mathrm{O}_{2}}$ which depends on the type of process and the production scale. Accounting for inflation from 2005 to 2014 gives a

\section{Table 2 Parameters used for FA example}

\begin{tabular}{|c|c|c|}
\hline Parameter & Value & Source \\
\hline$k_{L, \mathrm{O}_{2}} a$ & $6.0 \cdot 10^{-2} s^{-1}$ & (van 't Riet and Tramper 1991) \\
\hline $\mathrm{CO}_{2}$ & $6.0 \cdot 10^{-2} \mathrm{~mol} / \mathrm{m}^{3}$ & (Fu et al. 2010) \\
\hline $\mathrm{C}_{\mathrm{CO}_{2}}$ & $1.6 \mathrm{~mol} / \mathrm{m}^{3}$ & (Roa Engel et al. 2011) \\
\hline $\mathrm{D}_{\mathrm{O}_{2}}$ & $2.1 \cdot 10^{-9} \mathrm{~m}^{2} / \mathrm{s}$ & (Cussler 2009) \\
\hline $\mathrm{DCO}_{2}$ & $1.9 \cdot 10^{-9} \mathrm{~m}^{2} / \mathrm{s}$ & (Cussler 2009) \\
\hline$a_{p}$ & $5.3 \cdot 10^{-2} \mathrm{~kg}_{\mathrm{p}} /\left(\mathrm{kg}_{\mathrm{x}} \cdot \mathrm{h}\right)$ & (Roa Engel et al. 2011) \\
\hline$c_{x}$ & $50 \mathrm{~kg} x / \mathrm{m}^{3}$ & (Chang et al. 2014) \\
\hline $\mathrm{H}_{\mathrm{O}_{2}}$ & $5.11 \cdot 10^{9} \mathrm{~Pa}$ & (Lide 2009) \\
\hline $\mathrm{H}_{\mathrm{CO}_{2}}$ & $2.11 \cdot 10^{8} \mathrm{~Pa}$ & (Lide 2009) \\
\hline$V_{\text {mol }}$ & $1.81 \cdot 10^{-5} \mathrm{~m}^{3} / \mathrm{mol}$ & Calculated \\
\hline$\rho_{\mathrm{H}_{2} \mathrm{O}}$ & $9.94 \cdot 10^{2} \mathrm{~kg} / \mathrm{m}^{3}$ & (Lide 2009) \\
\hline$P_{\mathrm{O}_{2}}$ & $0.02-0.08 \$ / \mathrm{kg}_{\mathrm{O}_{2}}$ & (Sho Kobayashi and Hassel 2005) \\
\hline$P_{\mathrm{CO}_{2}}$ & $0.02-0.08 \$ / \mathrm{kg}_{\mathrm{CO}_{2}}$ & (Initiative 2012) \\
\hline$P_{\mathrm{Glc}}$ & $0.68 \$ / \mathrm{kg}_{\mathrm{Glc}}$ & $\begin{array}{l}\text { (United States Department of Agricul- } \\
\text { ture 2014) }\end{array}$ \\
\hline$P_{W}$ & $0.094 \$ / k W h$ & (Steelonthenet.com 2014) \\
\hline
\end{tabular}


range from 0.02 to $0.08 \$ / \mathrm{kg}_{\mathrm{O}_{2}}$. For $\mathrm{CO}_{2}$, the situation is more complex. $\mathrm{CO}_{2}$ consumption comes at a certain price when it is purchased as a refined gas because capture and transportation costs have to be covered. However, one could also argue that consumption of $\mathrm{CO}_{2}$ could add additional income to a process since the financial penalty for $\mathrm{CO}_{2}$ emission is set on $\mathrm{CO}_{2}$ emission in some countries. In theory, a $\mathrm{CO}_{2}$-consuming process could be coupled to a $\mathrm{CO}_{2}$-emitting process. Therefore, the financial penalty of the emitting process would be reduced and the savings can be counted as an income of the $\mathrm{CO}_{2}$-consuming process. For this study, it was decided to purchase a refined gas. The other scenario has too many uncertainties because it depends on too many factors. The costs for $\mathrm{CO}_{2}$ capture and transportation are in the range of $0.038-0.070 \$ / \mathrm{kg}_{\mathrm{CO}_{2}}$ according to a report of the National Enhanced Oil Recovery Initiative (NOERI). The range is close to the $\mathrm{O}_{2}$ price range, therefore it was decided to apply the same price range of $0.02-0.08 \$ / \mathrm{kg}$ for both pressurized gases. Gas prices at the high end of this range were used to evaluate the impact of different top pressures.

\section{Results of economic evaluation}

The resulting total costs $G_{\text {tot }}$ per kg FA for $b=0-1$ under these conditions are in the range of $10^{-1}-10^{-3} \$ / \mathrm{kg}_{\mathrm{FA}}$ (see Fig. 3) for both top pressures. For $p_{\text {tot }}=1$ atm, the lowest costs were calculated for cases 2 and 3 when the net $\mathrm{CO}_{2}$ production is $0(b=1 / 3)$. For both cases, the costs are equal at this $b$ value, which is caused due to the fact that the $\mathrm{CO}_{2}$ outflow of case 3 approaches 0 when no $\mathrm{CO}_{2}$ is produced. This reduces all other outflows to 0 as well, which essentially turns this system into an off-gas recycle system with a pure $\mathrm{O}_{2}$ feed. For case 2 , the costs increase linearly until $b=0$, and for case 3 they increase until $b=1$. The costs of cases 1 and 2 are the same when $b=0$. Case 1 reduces to case 2 , because the $\mathrm{O}_{2}$ outflow becomes 0 when $r_{\mathrm{O}_{2}}=0$ at $b=0$, and this removes all other outflow rates. For $r_{\mathrm{O}_{2}}>0$, the costs of case 1 are at a minimum at $b=0.19$. The costs are only slightly higher in this range than for case 2 . From this point on, the costs increase significantly, and the curve has an asymptote at $b=0.457$, at which the costs become infinitely high. This is caused by the fact that the optimal partial $\mathrm{O}_{2}$ pressure in the gas phase in the bioreactor increases as the $\mathrm{O}_{2}$ consumption rate increases, and as $b$ approaches 0.457 , the $\mathrm{O}_{2} / \mathrm{N}_{2}$ ratio in the outflow approaches the $\mathrm{O}_{2} / \mathrm{N}_{2}$ ratio of the inflow. This leads to an increase of all flow rates including the $\mathrm{CO}_{2}$ inflow. It should be noted that most of the added $\mathrm{CO}_{2}$ is lost to the off-gas. The fact that the outflow $\mathrm{O}_{2} / \mathrm{N}_{2}$ ratio approaches the inflow ratio causes that case 1 cannot be used for $b>0.457$. How the $b$ value of the asymptote of the cost curve of case 1 depends on pressure can be derived by substitution of Eqs. 35-37 and
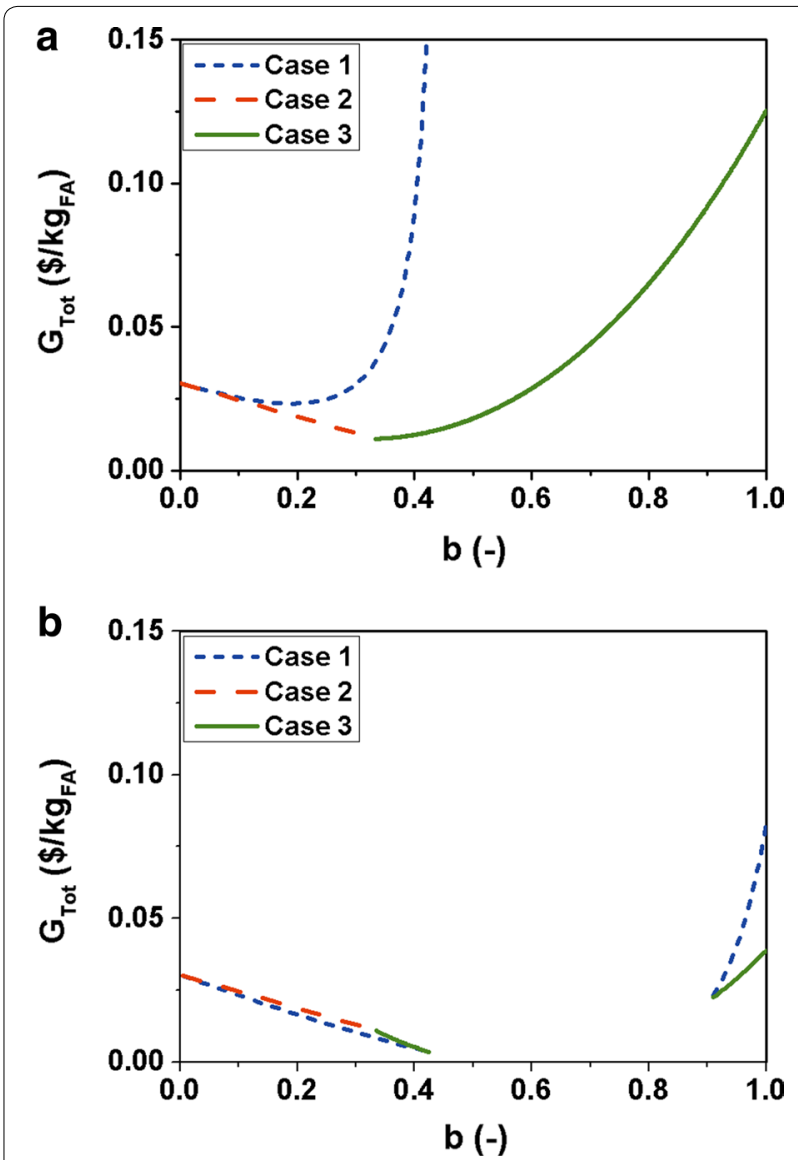

Fig. 3 Total gas supply costs of three different gas supply configurations: $\mathbf{a} p_{\text {tot }}=1 \mathrm{~atm}$ and $\mathbf{b} p_{\text {tot }}=2$ bar. Gas prices were taken as $0.08 \$ / \mathrm{kg}$

the process parameters into the denominator of the first term on the right-hand side of Eq. 20, setting the resulting expression equal to 0 , and solving it for $b$.

For $p_{\text {tot }}=2$ bar, the costs of case 2 are the same as for $p_{\text {tot }}=1$ bar, because they are independent of the top pressure (see Eqs. 23 and 24). Also the breakeven points of cases 1 and 2, and of cases 2 and 3 remain unchanged. Nonetheless, several differences are observed for the results of cases 1 and 3 . The most obvious ones are the gap in the cost curves of cases 1 and 3 between $b=0.42-0.91$ and their breakeven points at the start and end of the gap. Furthermore, the curves of cases 1 and 3 are stretched and the costs of both cases are lower than for $p_{\text {tot }}=1 \mathrm{~atm}$.

The gap in both curves is present because optimal conditions in the gas phase cannot be maintained with these cases in this range because the $\mathrm{O}_{2} / \mathrm{N}_{2}$ ratio of the inflow is too high. This is caused by the fact that the minimal $\mathrm{O}_{2} / \mathrm{N}_{2}$ ratio in the inflow is the $\mathrm{O}_{2} / \mathrm{N}_{2}$ ratio of air. This leads to the problem that insufficient $\mathrm{N}_{2}$ is fed to the bioreactor to strip sufficient $\mathrm{CO}_{2}$ from the liquid phase when aiming to maintain desired $\mathrm{O}_{2}$ pressures, which leads to 
increased $\mathrm{CO}_{2}$ concentrations. On the other side, if one increases the $\mathrm{N}_{2}$ inflow to maintain the desired $\mathrm{CO}_{2}$ pressure, there will be an overload of $\mathrm{O}_{2}$ supply. The only way to overcome this problem is to lower the $\mathrm{O}_{2} / \mathrm{N}_{2}$ ratio in the inflow, for example by adding additional $\mathrm{N}_{2}-\mathrm{a}$ configuration that is not considered here.

The breakeven points of cases 1 and 3 at the end and start of the gap occur because the flows of both cases are identical at these points. For case 1, the pure $\mathrm{CO}_{2}$ feed becomes 0 , and for case 3 , no pure $\mathrm{O}_{2}$ is added to the gas feed, which means that a pure air feed suffices to maintain the desired partial gas pressures within the vessel.

The stretching of the cost curve of case 1 is related to the fact that a higher top pressure increases the partial $\mathrm{O}_{2}$ pressure, and therefore higher transfer rates from gas to liquid phase can be achieved. Therefore, case 1 can be used up to $b=1$, when $r_{\mathrm{O}_{2}}$ is at its maximal value, except for the range of the gap, and the limitation for case 1 at $1 \mathrm{bar}$ is removed. Increasing the pressure even further (results not shown here) widens the gap. The end of the gap moves toward higher $b$ values until the curves on the right-hand side of the gap are completely removed, and the start of the gap approaches $b=1 / 3$.

The total costs of both cases are lowered when $p_{\text {tot }}$ is increased. For case 1, the costs become even slightly lower than those for case 2, and also loser than those of case 3 until their first breakeven point. The costs are higher than for case 3 after the second breakeven point. The difference between case 1 and the other two increases on the left-hand side of the gap when the pressure is elevated even further, and the difference between cases 1 and 3 decreases on the right-hand side. For case 3 , the costs decrease from $b=1 / 3$ to the first breakeven point in case 1 , in comparison to increasing from $b=1 / 3$ to 1 . The overall lower costs of both cases is due to the fact that the amounts of pure gases which are lost in the off-gas decrease and therefore also the pure gas feeds decrease. For case 2, the pure $\mathrm{O}_{2}$ costs also decrease, because more $\mathrm{O}_{2}$ from air can be used.

\section{Compression vs. gas costs}

For case 2, compression costs are absent because no air is used. For cases 1 and 3 at $p_{\text {tot }}=1$ bar, the costs are completely governed by the pure gas prices in the present model, because in- and outside pressures are equal and friction and hydraulic pressure are neglected. The evaluation of $p_{\text {tot }}$ to 2 bar shows an increasing trend for compression costs from $b=0$ to 1 for case 1 and 3, because the air inflow increases. The compression costs become dominant near the breakeven points of cases 1 and 3, and they are the only costs at the breakeven points (Fig. 4). Still, the general trend of the curves is governed by the gas costs.

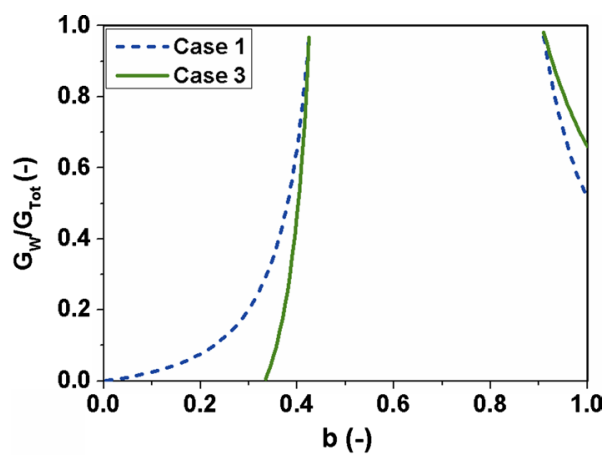

Fig. 4 Ratio of compression and total costs at $p_{\text {tot }}=2$ bar. Gas prices were taken as $0.08 \$ / \mathrm{kg}$

\section{Cost scenarios}

As discussed before, the costs of gaseous substrates are variable and strongly depend on the production method, location, and production scale. Four cost scenarios were evaluated at $p_{\text {tot }}=1.5$ bar to estimate the impact of different $\mathrm{O}_{2}$ and $\mathrm{CO}_{2}$ prices on the gas costs per $\mathrm{kg}$ FA (see Fig. 5). The general trend of the curves is unaffected by variations of $\mathrm{O}_{2}$ and $\mathrm{CO}_{2}$ prices except for cost scenario B. Here, the costs for case 2 increase for large $b$, instead of decreasing. Furthermore, this case is the only one in which case 1 leads to lower costs than the off-gas recycle and case 3 for $b>0$. Still, the costs are higher than those in case 3 for high $b$ values. Barely any differences are seen between cases 1 and 2 for cost scenarios A and C, but the costs of case 3 are lower than those for case 1 for $b=1 / 3-1$. However, the differences in costs of the three cases are less than $0.02 \$ / \mathrm{kg}_{\mathrm{FA}}$ in all scenarios, except for large $b$ values.

\section{Discussion}

The presented methodology has not been validated by experiments. One can consider the situation in which microbial strains would be engineered in such a way that the different $b$ values would be obtained at fermentation temperature, pressure, and composition such as proposed here. However, that would not make it possible to prove experimentally that full-scale fermentations show an economic optimum that agrees to our calculations.

\section{Economic evaluation}

Looking only at absolute costs which are directly related to gas supply, the differences between the three cases are very moderate, especially for increased top pressures. Depending on the $b$ value, either case 2 or case 3 should be used for low pressures. Only if $\mathrm{O}_{2}$ purchase costs are relatively low, such as in Fig. 5b, there are situations that case 1 is favorable. However, case 1 has one 

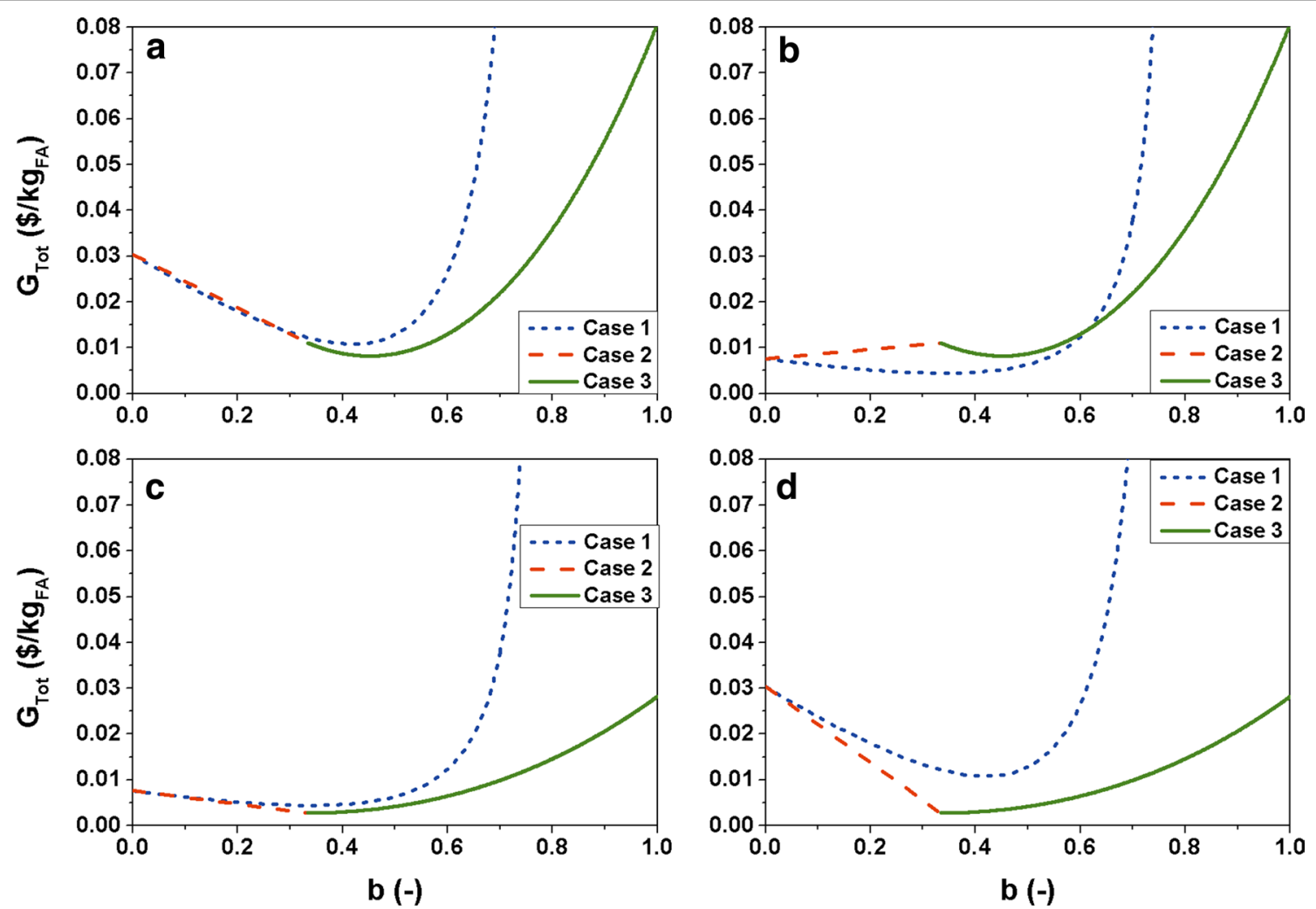

Fig. 5 Total costs for four different scenarios of high gas price $(0.08 \$ / \mathrm{kg})$ and low gas price $(0.02 \$ / \mathrm{kg})$ at $p=1.5$ bar. a $\mathrm{O}_{2}$ high, $\mathrm{CO}_{2}$ high, b $\mathrm{O}_{2}$ high, $\mathrm{CO}_{2}$ low, c $\mathrm{O}_{2}$ low, $\mathrm{CO}_{2}$ low, $\mathbf{d ~} \mathrm{O}_{2}$ low, $\mathrm{CO}_{2}$ high

major advantage over the other two cases, namely, it can be used for $\mathrm{CO}_{2}$-consuming and $\mathrm{CO}_{2}$-producing bioreactions. The other two cases can only be used when either $r_{\mathrm{CO}_{2}} \geq 0$ (case 3) or $r_{\mathrm{CO}_{2}} \leq 0$ (case 2). Furthermore, the results indicate that a metabolism that operates the fermentation near $b \approx 1 / 3$ can lead to the lowest costs in terms of gas supply. Energy costs for compression become relevant for elevated pressures. For $b<1 / 3$, compression costs are small compared to gas costs. However, they can take up to $100 \%$ of the total costs. This is the case when air does not need to be enriched with $\mathrm{O}_{2}$ and/ or $\mathrm{CO}_{2}$. Still, the general trend of the costs curves is governed by the gas costs. Increasing $p_{\text {tot }}$ lowers gas supply costs, but from a certain point on, too high pressures limit the application of cases 1 and 3, because desired conditions in the vessel cannot be maintained.

However, other costs than gas costs need to be considered to define metabolic engineering targets and for optimal bioreactor design. When including the glucose costs, the lowest costs are achieved when all FA is produced by the reductive part of the citrate cycle $(b=0)$, which means that only $\mathrm{CO}_{2}$ is consumed. This is caused by the fact that the costs for glucose per kg FA are one order of magnitude higher than gas supply costs, and therefore the costs are dominated by the glucose costs. Even though other costs, in particular feedstock costs, are dominant, choosing the best gas supply configuration can still save about $0.01 \$ / \mathrm{kg}$ product, translating into a million dollars per year for a product that might be produced at a scale of 100,000 tonnes per year. The questions that remain are to which extent FA can be produced by the reductive pathway, and to which extent the oxidative pathway needs to contribute to provide ATP.

\section{Methodology}

This study only considered fermentations at steady state. However, many fermentations are operated as batch, or fed-batch, leading to changing production rates in time. This raises the question whether the methodology still can be used for these modes of operation. If the time course of the production rates is known, and if at each point in time an optimum steady state can be achieved with respect to the gas supply rates, the costs for different cases can be plotted over the time of the (fed-) batch and the methodology can still be used. The optimization of gas supply rates needs to be included when more detailed models are used for process analysis and optimization. 
Furthermore, during the cost calculations the effect of hydrostatic pressure was neglected, which is valid for small-scale bioreactors. For large-scale bioreactors, the hydrostatic pressure can lead to substantial pressure gradients between top and sparger levels, roughly 1 bar per $10 \mathrm{~m}$, which leads to a higher power consumption. Additionally, the pressure drop along the bioreactor height implies that it will become more difficult to maintain the desired conditions in the liquid phase, because partial pressure in the gas phase will change from bottom to top.

Large-scale bioreactors also change the model to describe mass transfer between liquid and gas phases. In the current analysis, the bioreactor was considered to have a single compartment and both phases were assumed to be well mixed. This is valid for lab-scale bioreactors with a single impeller. However, the situation becomes more complex for larger vessels. According to van 't Riet and Tramper (1991), the gas phase of large-scale vessels (typically three times larger height than width) is best modeled using compartmentalization. Modeling of the hydrostatic pressure and the question of how to achieve optimal conditions in large-scale vessels is not addressed here, but it still needs to be considered during actual fermentor design.

\section{Other gases/fermentation}

It has been mentioned that DSM uses case 3 for commercial succinic acid fermentation (Table 1) to be able to keep a relatively high $\mathrm{CO}_{2}$ concentration in the bioreactor (Jansen and van Gulik 2014). Details are not available. For other fermentations such as those mentioned in Table 1 , the results may be very different, especially depending on the gas purchase prices. However, the methodology shown in this paper may be used in all cases.

\section{Conclusions}

The aim of this study was to compare different gas supply strategies for fermentations in which more than one substrate is a gaseous compound. A methodology to derive different gas supply strategies and subsequently calculate the size of each gas flow was presented. The methodology was applied to FA fermentation with $R$. delemar which needs $\mathrm{O}_{2}$ and $\mathrm{CO}_{2}$. Three different gas supply strategies were identified: (1) air supplemented with $\mathrm{CO}_{2}$ (vented off-gas), (2) off-gas recycled with pure $\mathrm{CO}_{2}$ and $\mathrm{O}_{2}$ feeds, and (3) air supplemented with $\mathrm{O}_{2}$. The costs directly related to gas supply are in the same order of magnitude for the three cases, but strongly depend on the $\mathrm{O}_{2}$ and $\mathrm{CO}_{2}$ prices and consumption rates, which leads to the lowest costs. Compression costs only become relevant for large $b$ values, and may exceed the gas purchase costs. However, the fermentation costs are dictated by the yield on glucose which is highest when all FA is produced via the anaplerotic route. The results clearly show that an off-gas recycle strategy does not necessarily lead to lower overall production costs, and for each fermentation it must be evaluated which strategy is most beneficial.

\section{Nomenclature}

a gas-liquid interfacial area per bioreactor liquid volume $\left[\mathrm{m}^{2} / \mathrm{m}^{3}\right]$

$c$

$C_{\mathrm{p}}$

$C_{\mathrm{V}}$

$D_{\mathrm{i}}$

F

$G_{\mathrm{i}} \quad$ costs per kilogram product $\left[\$ / \mathrm{kg}_{P}\right]$

$H \quad$ Henry's law constant $[\mathrm{Pa}]$

$k_{\mathrm{L}} \quad$ mass transfer coefficient in liquid phase $[\mathrm{m} / \mathrm{s}]$

$M \quad$ molar mass $[\mathrm{kg} / \mathrm{mol}]$

$P \quad$ price $\left[\$ / \mathrm{kg}_{i}\right]$ or $[\$ / \mathrm{J}]$

$p \quad$ pressure $[\mathrm{Pa}]$

$q \quad$ specific production rate $\left.\left[\mathrm{mol}_{i} /\left(\mathrm{kg}_{\mathrm{X}}\right]\right)\right]$

$r \quad$ production rate per bioreactor liquid volume $\left[\mathrm{mol} /\left(\mathrm{m}^{3} \mathrm{~s}\right)\right]$

$T$ mass transfer rate per bioreactor liquid volume $\left[\mathrm{mol} /\left(\mathrm{m}^{3} \mathrm{~s}\right)\right]$

$V_{\text {mol }} \quad$ molar volume $\left[\mathrm{m}^{3} / \mathrm{mol}\right]$

$W \quad$ work $\left[\mathrm{J} /\left(\mathrm{m}^{3} \mathrm{~s}\right)\right]$

$x \quad$ mole fraction in liquid phase $\left[\mathrm{mol}_{i} / \mathrm{mol}_{\text {tot }}\right]$

$y \quad$ mole fraction in gas phase $\left[\mathrm{mol}_{i} / \mathrm{mol}_{\text {tot }}\right]$

$\rho \quad$ density $\left[\mathrm{kg} / \mathrm{m}^{3}\right]$

$\kappa \quad$ ratio of specific heats at constant volume and at constant pressure [-]

\section{Subscripts}

$\begin{array}{ll}i, j & \text { for compounds } i \text { and } j \\ m & \text { for amounts in mass } \\ P & \text { for product } \\ \text { tot } & \text { for all components together } \\ W & \text { for work } \\ X & \text { for cell mass }\end{array}$

\section{Superscripts}

$\begin{array}{ll}\text { out } & \text { at outlet } \\ \text { in } & \text { at inlet } \\ \max & \text { maximum } \\ * & \text { at G/L interface }\end{array}$




\section{Abbreviations}

CAPEX: capital expenditures; FA: fumaric acid; OPEX: operation expenditures; OTR: oxygen transfer rate.

\section{Authors' contributions}

EH conceived of this study and carried out the computations. AS participated in the study design and coordination and helped to draft the manuscript. LW participated in the coordination and helped to draft the manuscript. All authors read and approved the final manuscript.

\section{Acknowledgements}

This work was carried out within the BE-Basic R\&D Program, which was granted an FES subsidy from the Dutch Ministry of Economic affairs, agriculture and innovation (EL\&l). Henk Noorman is acknowledged for critically reading the manuscript.

\section{Competing interests}

The authors declare that they have no competing interests.

Received: 21 December 2015 Accepted: 21 March 2016

Published online: 31 March 2016

\section{References}

Bäumchen C, Knoll A, Husemann B, Seletzky J, Maier B, Dietrich C, Amoabediny G, Büchs J (2007) Effect of elevated dissolved carbon dioxide concentrations on growth of Corynebacterium glutamicum on D-glucose and L-lactate. J Biotechnol 128(4):868-874. doi:10.1016/j.jbiotec.2007.01.001

Chang H, Kim M, Fei Q, Choi J-D-R, Shang L, Kim N-J, Kim J, Park H (2010) Economic evaluation of off-gas recycle pressure swing adsorption (PSA) in industrial scale poly(3-hydroxybutyrate) fermentation. Biotechnol Bioprocess Eng 15(6):905-910. doi:10.1007/s12257-010-0114-z

Chang HN, Jung K, Choi JDR, Lee JC, Woo HC (2014) Multi-stage continuous high cell density culture systems: a review. Biotechnol Adv 32(2):514-525. doi:10.1016/j.biotechadv.2014.01.004

Cussler EL (2009) Diffusion: mass transfer in fluid systems, 3rd edn. Cambridge University Press, New York

de Bont JAM, van Ginkel CG, Tramper J, Luyben KCAM (1983) Ethylene oxide production by immobilized Mycobacterium Py1 in a gas-solid bioreactor. Enzyme Microb Technol 5(1):55-59. doi:1 0.1016/0141-0229(83)90065-0

de Ory I, Romero LE, Cantero D (2004) Operation in semi-continuous with a closed pilot plant scale acetifier for vinegar production. J Food Eng 63(1):39-45. doi:10.1016/50260-8774(03)00280-2

Fu YQ, Li S, Chen Y, Xu Q, Huang H, Sheng XY (2010) Enhancement of fumaric acid production by Rhizopus oryzae using a two-stage dissolved oxygen control strategy. Appl Biochem Biotechnol 162(4):1031-1038. doi:10.1007/s12010-009-8831-5

Garcia-Ochoa F, Gomez E (2009) Bioreactor scale-up and oxygen transfer rate in microbial processes: an overview. Biotechnol Adv 27(2):153-176. doi:10.1016/j.biotechadv.2008.10.006

Green DW, Perry RH (2007) Perry's chemical engineers' handbook, 8th edn. McGraw-Hill, New York. doi:10.1036/0071422943

Hou C (1984) Propylene oxide production from propylene by immobilized whole cells of Methylosinus sp. CRL 31 in a gas-solid bioreactor. Appl Microbiol Biotechnol 19(1):1-4. doi:10.1007/BF00252808

Hurst KM, Lewis RS (2010) Carbon monoxide partial pressure effects on the metabolic process of syngas fermentation. Biochem Eng J 48(2):159-165. doi:10.1016/j.bej.2009.09.004

Initiative NEOR (2012) Carbon dioxide enhanced oil recovery: a critical domestic energy, economic, and environmental opportunity. http://www.neori. org/NEORI_Report.pdf. Accessed 02 Jul 2014
Jansen MLA, van Gulik WM (2014) Towards large scale fermentative production of succinic acid. Curr Opin Biotechnol 30:190-197. doi:10.1016/j. copbio.2014.07.003

Lide DR (ed) (2009) CRC handbook of chemistry and physics, 90th edn. CRC Press, Boca Raton

Liu K, Atiyeh HK, Stevenson BS, Tanner RS, Wilkins MR, Huhnke RL (2014) Continuous syngas fermentation for the production of ethanol, n-propanol and n-butanol. Bioresour Technol 151:69-77. doi:10.1016/j. biortech.2013.10.059

McIntyre M, McNeil B (1997) Effect of carbon dioxide on morphology and product synthesis in chemostat cultures of Aspergillus niger A60. Enzyme Microb Technol 21(7):479-483. doi:10.1016/S0141-0229(97)00007-0

Monteiro JS, de Queiroz Fernandes Araújo O, de Medeiros J (2009) Sustainability metrics for eco-technologies assessment, part l: preliminary screening. Clean Technol Environ Policy 11(2):209-214. doi:10.1007/ s10098-008-0189-9

Nagy E, Neubeck M, Mayr B, Moser A (1995) Simulation of the effect of mixing, scale-up and $\mathrm{pH}$-value regulation during glutamic acid fermentation. Bioprocess Eng 12(5):231-238. doi:10.1007/BF00369496

Papagianni M (2007) Advances in citric acid fermentation by Aspergillus niger: biochemical aspects, membrane transport and modeling. Biotechnol Adv 25(3):244-263. doi:10.1016/j.biotechadv.2007.01.002

Patel RN, Hou CT, Laskin Al, Felix A, Derelanko P (1980) Microbial oxidation of gaseous hydrocarbons: production of secondary alcohols from corresponding n-alkanes by methane-utilizing bacteria. Appl Environ Microbiol 39(4):720-726

Roa Engel CA, Straathof AJJ, Zijlmans TW, van Gulik WM, van der Wielen LAM (2008) Fumaric acid production by fermentation. Appl Microbiol Biotechnol 78(3):379-389. doi:10.1007/s00253-007-1341-x

Roa Engel CA, van Gulik WM, Marang L, van der Wielen LAM, Straathof AJJ (2011) Development of a low pH fermentation strategy for fumaric acid production by Rhizopus oryzae. Enzyme Microb Technol 48(1):39-47. doi:10.1016/j.enzmictec.2010.09.001

Sho Kobayashi $\mathrm{H}$, van Hassel B (2005) $\mathrm{CO}_{2}$ reduction by oxy-fuel combustion: economics and opportunities. http://www.gcep.stanford.edu/pdfs/ RxsY3908kaqwVPacX9DLcQ/kobayashi_coal_mar05.pdf. Accessed 02 Jul 2014

Sinnott RK (2005) Coulson and Richardson's chemical engineering — chemical engineering design, vol 6, 4th edn. Elsevier, Amsterdam

Song H, Lee JW, Choi S, You JK, Hong WH, Lee SY (2007) Effects of dissolved $\mathrm{CO}_{2}$ levels on the growth of Mannheimia succiniciproducens and succinic acid production. Biotechnol Bioeng 98(6):1296-1304. doi:10.1002/ bit.21530

Steelonthenet.com (2014) Conversion costs for BOF steelmaking. http://www. steelonthenet.com/cost-bof.html. Accessed 02 Jul 2014

Straathof AJJ (2011) The proportion of downstream costs in fermentative production processes. In: Moo-Young M (ed) Comprehensive biotechnology, vol 2, 2nd edn. Elsevier, Amsterdam, pp 811-814. doi:10.1016/ B978-0-08-088504-9.00492-X

United States Department of Agriculture (2014) US wholesale list price for glycose syrup, midwest markets, monthly, quarterly, and by calendar and fiscal year. http://www.ers.usda.gov/datafiles/Sugar_and_Sweeteners_ Yearbook_Tables/World_and_US_Sugar_and_Corn_Sweetener_Prices/ TABLE07.XLS. Accessed 02 Jul 2014

van 't Riet K, Tramper J (1991) Basic bioreactor design. Marcel Dekker Inc, New York

Zelle RM, de Hulster E, Kloezen W, Pronk JT, van Maris AJA (2010) Key process conditions for production of $\mathrm{C} 4$ dicarboxylic acids in bioreactor batch cultures of an engineered Saccharomyces cerevisiae strain. Appl Environ Microbiol 76(3):744-750 